\title{
Antihypertensive effects of edible brown seaweeds in rats
}

\author{
Faezah Sabirin ${ }^{1,2, *}$, Khoo Kong Soo ${ }^{3}$, Hoe See Ziau ${ }^{1}$, Lam Sau Kuen ${ }^{1}$ \\ ${ }^{1}$ Department of Physiology, Faculty of Medicine, University of Malaya, 50603 Kuala Lumpur, Malaysia \\ ${ }^{2}$ Centre of Preclinical Science Studies, Faculty of Dentistry, Universiti Teknologi MARA, Sungai Buloh Campus, Jalan Hospital, \\ 47000 Sungai Buloh Selangor, Malaysia \\ ${ }^{3}$ Department of Chemical Science, Faculty of Science, University Tunku Abdul Rahman, 31900 Kampar, Perak, Malaysia
}

\section{A R T I C L E I N F 0}

\section{Article history:}

Received 22 July 2016

Received in revised form

7 September 2016

Accepted 29 September 2016

\section{Keywords:}

Ant hypertension

Brown seaweeds

Blood pressure

Spontaneously hypertensive rats (SHR)

\begin{abstract}
A B S T R A C T
The present study is focused to evaluate the effect of three different brown seaweeds on blood pressure and heart rate (HR) using spontaneously hypertensive rats (SHR) and normotensive Wistar-Kyoto (WKY) rats. The seaweeds, Turbinaria ornata (T. ornata), Sargassum species (Sargassum sp.) and Padina tetrastromatica (P. tetrastromatica), were extracted in cold water and freeze-dried. Anaesthetised rats were prepared for direct blood pressure measurements with the changes in HR also being monitored. Rats were administered intravenously with the aqueous extract of the seaweeds at doses of 2.5 to $20.0 \mathrm{mg} / \mathrm{kg}$. Concentrations of $\mathrm{Na}^{+}, \mathrm{K}^{+}, \mathrm{Ca}^{2+}$ and $\mathrm{Mg}^{2+}$ found in the dose of $20.0 \mathrm{mg} / \mathrm{kg}$ of the marine plant extracts were determined. Subsequently, salt solutions containing the equivalent cationic concentration found in each of the seaweed extracts were tested on Sprague-Dawley (SD) rats. All seaweeds investigated produced significant $(\mathrm{P}<0.05)$ reductions in the blood pressure of both SHR and the control WKY rats. In T. ornata, significant $(\mathrm{P}<0.05)$ HR reducing effect was produced. In contrast, this effect was not seen in other brown seaweeds tested. Analysis of the ionic composition present in all the extracts revealed that the salt solution with equivalent ionic content of each seaweed extract did not produce any significant decrease in blood pressure of the SD rats. In conclusion, the data obtained from the present study suggest that the aqueous extracts of $T$. ornata, Sargassum sp. and P. tetrastromatica may contain blood pressure lowering agents.
\end{abstract}

(C) 2016 The Authors. Published by IASE. This is an open access article under the CC BY-NC-ND license (http://creativecommons.org/licenses/by-nc-nd/4.0/).

\section{Introduction}

Seaweeds are believed to have many benefits to human health since the ancient times. This is evident when references pertaining algae usage for remedies are recorded in early Chinese, Indian, Roman and Greek literatures.

The seaweeds are marine algae from the plant kingdom. They are classified into Phaeophyta (brown seaweed), Chlorophyta (green seaweed) and Rhodophyta (red seaweed) based on their nutritional value, as well as their chemical composition (Dawczynski et al., 2007). Generally, the brown seaweeds can be found along the tropical shores, worldwide (Prathep et al., 2007). Ooi et al. (2006) analysed seaweed distribution in Malaysia

\footnotetext{
* Corresponding Author.

Email Address: drfaezah@salam.uitm.edu.my (F. Sabirin)

https://doi.org/10.21833/ijaas.2016.09.015

2313-626X/C 2016 The Authors. Published by IASE.

This is an open access article under the CC BY-NC-ND license

(http://creativecommons.org/licenses/by-nc-nd/4.0/)
}

and reported that similar genus distribution pattern were observed along the Malaysian shores. At the species level however, wide variation of seaweed were noted (Ooi et al., 2006). In term of size, the brown seaweeds are greatly varied from giant kelp (20 m long) to the smaller species from 30 to $60 \mathrm{~cm}$ in length. Some of the brown seaweeds are edible including Turbinaria ornata (T. ornata), Sargassum species (Sargassum sp.) and Padina tetrastromatica (P. tetrastromatica).

Looking from the perspective of traditional medicine, the brown seaweeds have been used in folk medicine for blood pressure control. Furthermore, the brown seaweeds have been used in traditional Chinese medicine for cases of hypertension since it was believed to have the ability to lower the blood pressure (Lu, 1986). In the modern days, several biological activities of brown seaweeds have been discovered. There are reports on the activity of brown seaweeds as antioxidant (Cox et al., 2010; Kuda et al., 2005), antibacterial (Natrah et al., 2015; Stirk et al., 2007), antifungi 
(Aruna et al., 2010), antiviral (Hoe et al., 2009; Lee et al., 2004), anti-tumour (Kong et al., 2009) and antithyroiditis (Song et al., 2011) properties. Although the scientific evidence and the efficacy of brown seaweeds as antihypertensive agents is still lacking, the blood pressure lowering effect of some commonly consume Japanese seaweeds, the Undaria pinnatifida (wakame), Laminaria japonica (kombu) and Meristotheca papulosa (tosaka) in spontaneously hypertensive rat (SHR) has been scientifically documented (Tomomi et al., 2005).

The blood pressure is the force of blood that is exerted on the blood vessel wall per unit area (Guyton, 1991) and functions as the driving force to move blood through the circulatory system. The determinant of blood pressure is cardiac output (CO) and total peripheral resistance (TPR), where in stroke volume (SV) and heart rate (HR) are the factors that govern the $\mathrm{CO}$, while vascular factors affect the TPR (Guyton, 1991). In practise, blood pressure is not determined by measuring the $\mathrm{CO}$ or TPR, instead by measuring the arterial blood pressure. The measured arterial blood pressure is then represented by the systolic (SBP) and diastolic (DBP) blood pressures. Increment of any of the blood pressure determinant on the other hand, will produce hypertension.

Hypertension is abnormally high blood pressure in the arteries (Guyton, 1991), and in humans is defined and diagnosed based on the guidelines by the World Health Organisation (WHO), as well as the Joint National Committee on Prevention, Detection, Evaluation, and Treatment of High Blood Pressure (Chobanian et al., 2003) recommendations. The latest published WHO and JNC reports suggest that the normal blood pressure should be less than $120 / 80 \mathrm{mmHg}$ and any individual with blood pressure $>140 / 90$ is considered hypertension. Furthermore, in the Seventh JNC 2003 guidelines, a new category has been introduced that is the prehypertension class with the blood pressure of 120-139/80-89 mmHg.

In general, The SBP and DBP values can be measured using two techniques, the direct and indirect methods. For research and experimental purposes, the most commonly used direct method is the cannulation of the carotid artery of experimental animal model, while the indirect method is the tailcuff technique (Kurtz et al., 2005). Although the direct method is an invasive procedure, it is the most widely used method in research. Perhaps, this is due to the fact that the direct method offers a more comprehensive monitoring of the highly dynamic nature of the blood pressure than the indirect method. The technique is versatile and can be used effectively for acute studies in anesthetised animals or for long-term, continuous monitoring of arterial pressure in conscious animal models (Kurtz et al., 2005).

The animal models of hypertension share many features which are common to human hypertension. In fact, many of these models were developed by utilizing the etiological factors that are presumed to be responsible for human hypertension such as excessive salt intake, hyperactivity of the reninangiotensin system (RAS) and genetic factors (Badyal et al., 2003). The SHR for example, was originally bred from the Wistar rats (Okamoto, 1969) that was selectively bred through phenotypicdriven technique for hypertensive rats (Lerman et al., 2005).

Although rats are generally used as models for hypertension (Kurtz et al., 2005), other animals such as rabbits, monkeys, pigs and mice have also been employed to produce experimental hypertension (Badyal et al., 2003). Since the SHR appeared to have similar pathophysiological features to hypertension in humans (Sun and Zhang, 2005), the SHR is preferred. As a control to the SHR, the most commonly used normotensive rat is the WistarKyoto (WKY) rat which was bred from the descendants of the original normotensive strain of the WKY (Yamori, 1994).

Although there are several reports on various properties of seaweeds, most of the studies were done using the non-polar extracts whereas those in aqueous ones have been rarely investigated (Kuda et al., 2005). However, since seaweeds were traditionally prepared cooked in soups or simply eaten raw, aqueous extraction remains the closest to that prepared by the folks for the treatment of hypertension. Despite of their use as remedy for high BP, more scientific discoveries is needed to support the folkloric claim.

Conceptually, interference of any of the blood pressure determinants by antihypertensive agents will result in reduced blood pressure (Cowley, 1992). However, since the seaweeds live in the sea, they absorb and contain the ionic elements of the seawater they grow in which include sodium and potassium ions (Rizvi and Shameel, 2005). The potassium ions may reduce the blood pressure by counteracting the effect of sodium in the body. In addition, there were reports on potassium and calcium rich diet which caused reduction in the blood pressure of adults (Chobanian and Hill, 2000; Van Leer and Seidell, 1995) and similar results were also documented from magnesium rich diet (Hatzistavri et al., 2009; Van Leer and Seidell, 1995). The ionic composition of the seaweed extracts should therefore be considered and their effect on rats should be validated. This is important to eliminate doubt on the result later. By confirming the ionic content and its effect on rats, any hypotensive effects obtained following the administration of the tested samples were certainly from the potential of the extracts.

The present study was therefore designed to investigate the antihypertensive effect of aqueous extracts of selected seaweeds, T. ornata, Sargassum sp. and P. tetrastromatica on SHR and its controls, the WKY rats.

\section{Material}


In this present study, three types of brown seaweeds were used. They are the Turbinaria ornata (T. ornata), Sargassum species (Sargassum sp.) and Padina tetrastomatica (P. tetrastromatica). Whole seaweeds and sponge were collected from Tanjung Tuan, Port Dickson in Negeri Sembilan. The seaweed samples were sent to Universiti Tunku Abdul Rahman (UTAR), Kuala Lumpur, for identification. Each seaweed specimen were then prepared and deposited to Herbarium of Faculty of Science, UTAR at Kampar, Perak. The voucher numbers are: UTAR/FSC/10/002 for T. ornata, UTAR/FSC/10/003 for Sargassum sp. and UTAR/FSC/10/004 for $P$. tetrastromatica.

In this experiment, adult male WKY and SHR rats, weighing 250 - $300 \mathrm{~g}$, were obtained from the Experimental Animal Center, University of Malaya. They were all kept under standard conditions, and given tap water and standard rat chow ad libitum. For each seaweed sample, six hypertensive (SHR, $n=6$ ) and normotensive (WKY, $n=6$ ) rats were used. All experiment procedures were approved by the University of Malaya Medical Center Animal Ethics Committee (Ethic Reference No.: FIS/29/04/2010/LSK (R)).

A physiographic recording system, the PowerLab equipped with a bridge amp (model ML221), Data Acquisition Systems (model ML865) and a reusable BP transducer (model MLT0380) from AD Instruments Pty. Ltd., Australia was used for blood pressure monitoring and recording.

\section{Methods}

\subsection{Extraction of the seaweeds}

The freshly collected seaweed samples were quickly rinsed with tap water to remove salt, debris and extraneous material. The samples were refrigerated at $-20^{\circ} \mathrm{C}$ and later freeze-dried. The dried samples were then placed in a mortar and subsequently ground into powder form using a blender. Sunsequently, $10 \mathrm{~g}$ of each of the powdered materials were separately stirred overnight in 100 $\mathrm{mL}$ of deionised water at $4^{\circ} \mathrm{C}$. The aqueous extracts obtained from each seaweed were then filtered through a Whatman No. 1 filter paper. The residue was reconstituted with $100 \mathrm{~mL}$ of deionised water and stirred overnight at $4{ }^{\circ} \mathrm{C}$. The extracts obtained were filtered and pooled with the initial extracts. The aqueous extracts were lyophilised to obtain its final aqueous product. The lyophilised samples were then collected and stored at $-20^{\circ} \mathrm{C}$ for future use.

Fresh seaweed aqueous extracts were prepared using $0.9 \% \mathrm{NaCl}$ before each experiment. The extracts were then tested on the rats to investigate its hypotensive potentials.

\subsection{Experimental setup for the animal study}

Rats were anaesthetised with pentobarbital sodium $50 \mathrm{mg} / \mathrm{kg}$, through intraperitoneal (i.p.) injection. Each anaesthetised rat was placed in a supine position on a surgical board. The right jugular and left femoral veins, and left carotid artery and trachea were located and surgically exposed. The jugular vein was then cannulated with polyethylene tubing for intravenous (i.v.) injections of the samples. The femoral vein was also cannulated for i.v. injections of subsequent doses of pentobarbital sodium $(5.0 \mathrm{mg} / \mathrm{kg}$ ) whenever required. The carotid artery was cannulated with a polyethylene cannula to monitor the BP through a pressure transducer that was connected to the PowerLab recording system. All the tubes were filled with heparinised saline $(10 \mathrm{U} / \mathrm{mL})$ to avoid any blood coagulation possibilities. The trachea was cannulated in order to facilitate spontaneous breathing. Small animal electrographic leads were attached to the limbs of the rat to monitor the HR, with electrocardiogram tracing. The rat's body temperature was kept warm $\left(35 \pm 2^{\circ} \mathrm{C}\right.$ ) with a heating lamp throughout the experiment. The setup was allowed to equilibrate for at least 30 minutes before experiments begin.

After the equilibrium period, test samples were administered in bolus injections via the cannulated jugular vein. Each injection was standardised to a fixed volume of $0.1 \mathrm{~mL}$ per $300 \mathrm{~g}$ body weight. The blood pressure changes were monitored and allowed to return to the resting level before subsequent injection was given. The average recovery period after each administration was about 30 minutes. The blood pressure changes due to the administration of the extracts were obtained by calculating the difference between the blood pressure before and the lowest blood pressure reading recorded after the injections.

The mean arterial pressure (MAP) was then calculated from the following formula:

$$
M A P=D B P+1 / 3(S B P-D B P)
$$

\subsection{Estimation of the ionic contents of the brown seaweed extracts}

The concentration of major ionic elements (i.e. $\mathrm{Na}^{+}, \mathrm{K}^{+}, \mathrm{Ca}^{2+}$ and $\mathrm{Mg}^{2+}$ ) of the seaweed extracts were estimated using Inductively Coupled Plasma Optical Emission Spectrometry (ICP-OES 5300DV). Each element has identified wavelength based on its molecular weight and programmed to the machine via the Optima WinLab 32 Software. The machine can analyse in axial and radial views depending on the specific wavelengths of each ion. The operating parameters used are given in Table 1.

\subsection{Effect of the cationic content on blood pressure of rats}

Salt solutions with equivalent ionic content of that present in each seaweed extract were then prepared and injected i.v. in Sprague-Dawley (SD) rats. The changes in $\mathrm{HR}$ and $\mathrm{BP}$ were monitored through the PowerLab recording system and the maximal changes were identified and analysed. 
Table 1: Operating parameters for ICP-OES 5300DV

\begin{tabular}{|c|c|c|}
\hline Element & Wavelength $(\mathrm{nm})$ & View \\
\hline $\mathrm{Na}^{+}$ & 589.592 & Radial \\
\hline $\mathrm{K}^{+}$ & 766.490 & Radial \\
\hline $\mathrm{Ca}^{2+}$ & 315.887 & Radial \\
\hline $\mathrm{Mg}^{2+}$ & 279.081 & Radial \\
\hline
\end{tabular}

\section{Data analysis}

The data of cardiovascular parameters obtained from the PowerLab recording system were exported and analysed using Excel 2010 and SPSS program for Windows. Statistical comparisons of physiological variables were made using paired t-test in determining the significance level. Comparison between and among doses tested were determined using one-way ANOVA and Post-Hoc test (Duncan). The statistical significance was set at $\mathrm{P}<0.05$. Results are presented as mean \pm standard error of mean (S.E.M.).

\section{Results and discussion}

In the present study, observation of decreased blood pressure was evident with all the three brown seaweeds investigated, but with varying degrees of efficacy. Fig. 1 shows a sample of recorded tracing of blood pressure changes in SHR following administration of one of the seaweed extracts.

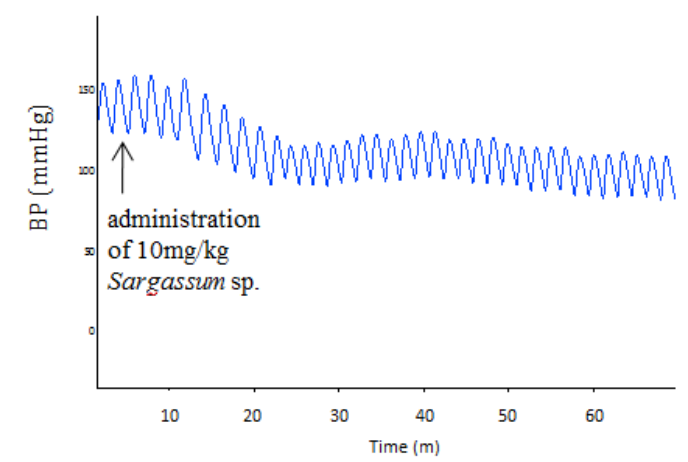

Fig. 1: Sample of recorded tracing of blood pressure changes in SHR following administration of an extract $\mathrm{X}$-axis: compressed passage of time

The aqueous extract of all the three types of brown seaweeds showed various degrees of blood pressure reduction effects in both anaesthetised SHR and WKY rats. Anaesthesia was done using pentobarbitone sodium $(50 \mathrm{mg} / \mathrm{kg})$ as it is widely used in veterinary and preclinical medicine (Katsuda et al., 2000). In addition, rats that was anaesthetised with pentobarbitone sodium were not susceptible to external disturbances that may lead to fluctuations in the blood pressure, and therefore, a stable experimental condition can be established for the study (Katsuda et al., 2000). In this study, the MAP value is used as the blood pressure indicator, as it is the average effective pressure that considers both the SBP and DBP that drives blood through the systemic organs (Mohrman, 1997).
The most significant $(\mathrm{P}<0.001)$ blood pressure reductions produced by $T$. ornata extracts were observed at the dose of $2.5 \mathrm{mg} / \mathrm{kg}$ in SHR only (Fig. 2). The T. ornata extracts however, did not produce greater reduction of MAP in the SHR when compared to the normotensive, WKY rats. Although the blood pressure reduction of $T$. ornata extracts appeared to be in a dose-dependent manner, they were not statistically significant.

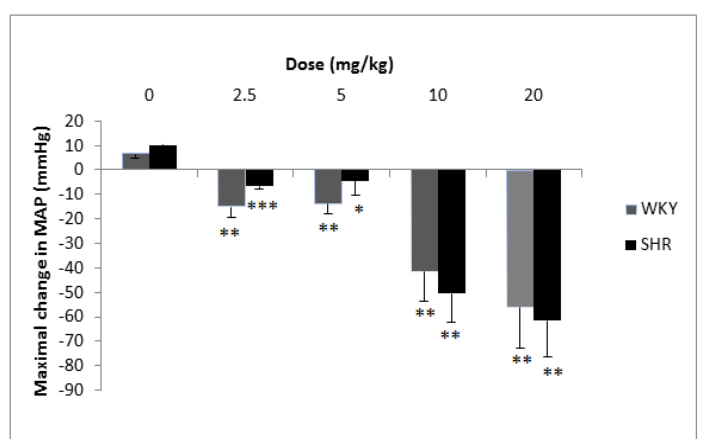

Fig. 2: Effect of T. ornata on the MAP of anaesthetised rats. Values are mean \pm S.E.M. $(\mathrm{n}=6) .{ }^{*} \mathrm{P}<0.05$; ${ }^{* *} \mathrm{P}<0.01$ and ${ }^{* * *} \mathrm{P}<0.001$ as compared with the respective controls.

The aqueous extracts of Sargassum sp. produced significant blood pressure reduction in SHR and WKY rats at the dose of $20 \mathrm{mg} / \mathrm{kg}$. At the lower doses, significant hypotensive effects were only seen in the SHR (Fig. 3). The most significant $(\mathrm{P}<0.01)$ hypotensive effects produced by aqueous extracts of $P$. tetrastromatica was observed at the highest dose tested of $20 \mathrm{mg} / \mathrm{kg}$ in SHR only (Fig. 4).

Although all the brown seaweeds extract investigated showed significant $(\mathrm{P}<0.05)$ blood pressure reduction in SHR and WKY rats, there was no significant difference between the effects seen in the SHR when compared to WKY rats. Thus, suggesting that the depressor response seems to be non-specific. In contrast to the effects on blood pressure, brown seaweeds tested did not affect the HR with equal degrees of potency. In fact, only $T$. ornata was able to produce significant $(\mathrm{P}<0.05)$ bradycardia in the SHR (Fig. 5). This suggests that only $T$. ornata may contain negative chronotropic effect substances while Sargassum sp. and $P$. tetrastromatica may contain principles that act on the blood vessels, which caused vasorelaxation and thus reduce the TPR and resulted in reduced blood pressure.

The analysis of ionic content of all the brown seaweeds tested showed presence of major ionic components (Table 2). The results were in agreement with Rizvi and Shameel, 2005 who reported large quantities of $\mathrm{Na}^{+}, \mathrm{K}^{+}, \mathrm{Ca}^{2+}$ and $\mathrm{Mg}^{2+}$ content in the seaweeds. Although they were from the same seaweed classification, the ionic content were differs from one another. This is due to the fact that seaweeds tend to accumulate elements from the seawater they grow in (Chapman and Chapman, 1980) and a particular type of seaweed would preferentially accumulate specific mineral element compared to another (Rizvi and Shameel 2005). This 
explained the variation of ionic concentration seen among the three brown seaweeds.

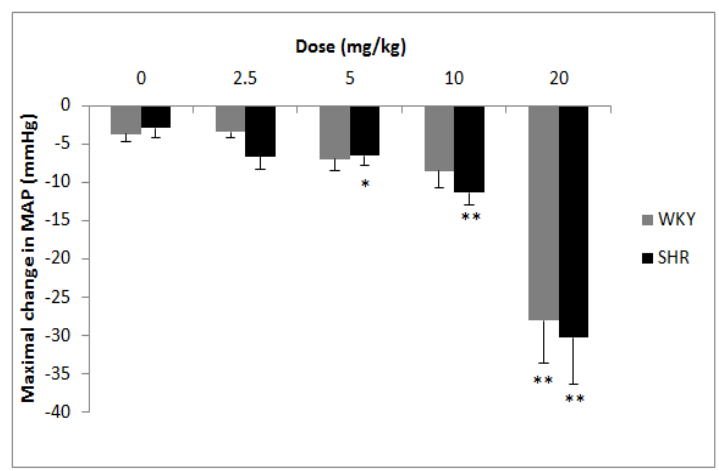

Fig. 3: Effect of Sargassum sp. on the MAP of anaesthetised rats. Values are mean \pm S.E.M. $(\mathrm{n}=6) .{ }^{*} \mathrm{P}<$ 0.05 and ${ }^{* *} \mathrm{P}<0.01$ as compared with the respective controls.

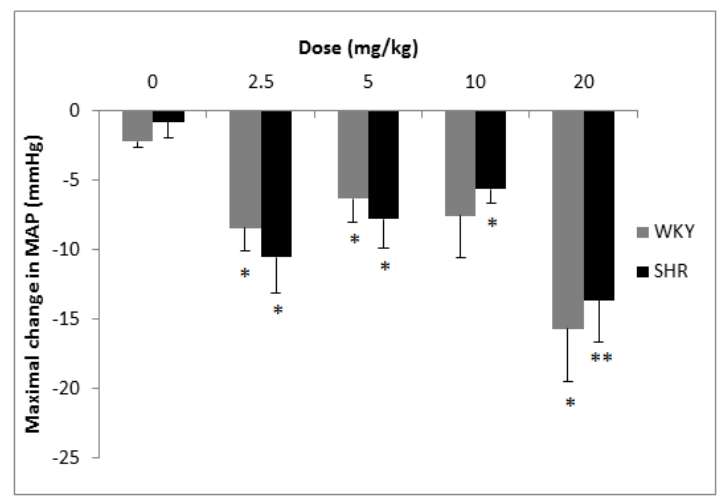

Fig. 4: Effect of $P$. tetrastromatica on the MAP of anaesthetised rats. Values are mean \pm S.E.M. $(n=6) .{ }^{*} \mathrm{P}<$ 0.05 ; $^{* *} \mathrm{P}<0.01$ and ${ }^{* * *} \mathrm{P}<0.001$ as compared with the respective controls.

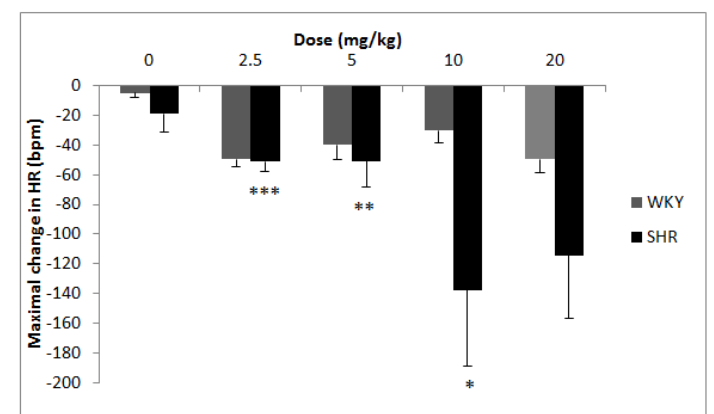

Fig. 5: Effect of T. ornata on the HR of anaesthetised rats Values are mean \pm S.E.M. $(\mathrm{n}=6) .{ }^{*} \mathrm{P}<0.05 ;{ }^{* *} \mathrm{P}<0.01$ and ${ }^{* * *} \mathrm{P}<0.001$ as compared with the respective controls.

Table 2: Major ionic composition of selected brown

\begin{tabular}{|cc|c|c|c|}
\multirow{2}{*}{$\begin{array}{c}\text { Seaweed/marine } \\
\text { sponge }\end{array}$} & \multicolumn{2}{c}{ Ionic Compositions $(\mathbf{m g} / \mathbf{g}$ extract) } \\
\cline { 2 - 5 } T. ornata & $\mathbf{\mathbf { N a } ^ { + }}$ & $\mathbf{\mathbf { M g } ^ { 2 + }}$ & $\mathbf{K}^{+}$ & $\mathbf{C a}^{\mathbf{2 +}}$ \\
\hline Sargassum & 51.56 & 9.64 & 202.35 & 7.69 \\
\hline P. tetrastromatica & 72.11 & 16.00 & 64.80 & 0.67 \\
\hline
\end{tabular}

The administrations of salt solutions containing equivalent concentrations to the ionic contents present in a dose of $20 \mathrm{mg} / \mathrm{kg}$ of each seaweed extracts into SD rats $(n=6)$ did not produce any significant changes in the MAP of the anaesthetised rats. Although the T. ornata extracts contained much higher element of potassium ion compared to the other two tested brown seaweed extracts, that concentration of potassium did not cause significant changes to the blood pressure value. The effect of the ionic composition particularly the potassium concentration is an important factor to be cleared off since it is a vasoactive element (Haddy et al., 2006). The potassium ions have been demonstrated to cause vasodilation results from hyperpolarization of the vascular smooth muscle cell (Haddy et al., 2006). Possibly, the concentration of the potassium ion was not high enough to cause the hypotensive effect. The blood pressure reductions seen in the study were therefore produced by the potential antihypertensive agents present in the seaweed extracts.

\section{Conclusions}

Based on the results obtained, the T. ornata, Sargassum sp. and $P$. tetrastromatica aqueous extracts contain potential hypotensive agent. The active compounds are extractable by water. The compounds in the extracts of $T$. ornata appear to act on the heart by significantly reducing the HR. On the other hand, active compounds in the aqueous extracts of Sargassum sp. and P. tetrastromatica seem to act entirely on the blood vessels. This information also serves as a piece of scientific evidence that partially validate the use of seaweeds in folk medicine for managing hypertension.

\section{Acknowledgment}

We would like to thank the students of University of Tunku Abdul Rahman who were involved in collecting the seaweeds and Mr Johgalingam for his excellent technical support.

\section{References}

Aruna P, Mansuya P, Sridhar S, Kumar IS and Babu S (2010). Pharmacognostical and antifungal activity of selected seaweeds from gulf of Mannar Region. Recent Research in Science and Technology, 2(1): 115-119.

Badyal DK, Lata H and Dadhick AP (2003). Animal model of hypertension and effect of drugs. Indian Journal of Pharmacology, 35(6): 349-362.

Chapman VJ and Chapman DJ (1980). Seaweeds and their uses. $3^{\text {rd }}$ Edition, Chapman and Hall, New York, USA.

Chobanian AV and Hill M (2000). National heart, lung, and blood institute workshop on sodium and blood pressure a critical review of current scientific evidence. Hypertension, 35(4): 858-863.

Chobanian AV, Bakris GL, Black HR, Cushman WC, Green LA, Izzo Jr JL and Roccella EJ (2003). The seventh report of the joint national committee on 
prevention, detection, evaluation, and treatment of high blood pressure: the JNC 7 report. Jama, 289(19): 2560-2571.

Cowley AWJ (1992). Long-term control of arterial blood pressure. Physiological Reviews, 72(1): 231-300.

Cox S, Abu-Ghannam N and Gupta S (2010). An assessment of the antioxidant and antimicrobial activity of six species of edible Irish seaweeds. International Food Research Journal, 17: 205220.

Dawczynski C, Schubert R and Jahreis G (2007). Amino acids, fatty acids, and dietary fibre in edible seaweed products. Food Chemistry, 103(3): 891-899.

Guyton AC (1991). Blood pressure control--special role of the kidneys and body fluids. Science, 252(5014): 1813-1816.

Haddy FJ, Vanhoutte PM and Feletou M (2006). Role of potassium in regulating blood flow and blood pressure. American Journal of PhysiologyRegulatory, Integrative and Comparative Physiology, 290(3): R546-R552.

Hatzistavri LS, Sarafidis PA, Georgianos PI, Tziolas IM, Aroditis CP, Zebekakis PE and Lasaridis AN (2009). Oral magnesium supplementation reduces ambulatory blood pressure in patients with mild hypertension. American Journal of Hypertension, 22(10): 1070-1075.

Hoe SJ, Hwang JY, Choi JI, Han JS, Kim HJ and Jeon YJ (2009). Diphlorethohydroxycarmalol isolated from Ishige okamurae, a brown algae, a potent $\alpha$ glucosidase and $\alpha$-amylase inhibitor, alleviates postprandial hyperglycemia in diabetic mice. European Journal of Pharmacology, 615(1): 252256.

Katsuda SI, Waki H, Nagayama T, Yamasaki M, O-Ishi H, Katahira K and Shimizu T (2000). Timedependent change in baroreflex control capacity of arterial pressure by pentobarbital anesthesia in rabbits. Experimental Animals, 49(2): 111-118.

Kong CS, Kim JA, Yoon NY and Kim SK (2009). Induction of apoptosis by phloroglucinol derivative from Ecklonia cava in MCF-7 human breast cancer cells. Food and Chemical Toxicology, 47(7): 1653-1658.

Kuda T, Tsunekawa M, Goto H and Araki Y (2005). Antioxidant properties of four edible algae harvested in the Noto Peninsula, Japan. Journal of Food Composition and Analysis, 18(7): 625-633.

Kurtz TW, Griffin KA, Bidani AK, Davisson RL and Hall JE (2005). Recommendations for blood pressure measurement in humans and experimental animals part 2: blood pressure measurement in experimental animals. A statement for professionals from the Subcommittee of Professional and Public
Education of the American Heart Association Council on High Blood Pressure Research. Arteriosclerosis, Thrombosis, and Vascular Biology, 25(3): 299-310.

Lee YS, Shin KH, Kim BK and Lee S (2004). AntiDiabetic activities of fucosterol fromPelvetia siliquosa. Archives of Pharmacal Research, 27(11): 1120-1122.

Lerman LO, Chade AR, Sica V and Napoli C (2005). Animal models of hypertension: an overview. Journal of Laboratory and Clinical Medicine, 146(3): 160-173.

Lu HC (1986). Chinese system of food cures. Sterling Publishing Co., New York, USA.

Mohrman DE (1997). Cardiovascular physiology. 4th Edition, McGraw-Hill, New York, USA.

Natrah FMI, Harah ZM, Japar Sidik NI and SYAHIDAH, A (2015). Antibacterial activities of selected seaweed and seagrass from port dickson coastal water against different aquaculture pathogens. Sains Malaysiana, 44(9): 1269-1273.

Okamoto K (1969). Spontaneous hypertension in rats. International Review of Experimental Pathology, 7: 227-270.

Ooi MK, Auld TD, and Whelan RJ (2006). Dormancy and the fire-centric focus: germination of three Leucopogon species (Ericaceae) from southeastern Australia. Annals of Botany, 98(2): 421430.

Prathep A, Wichachucherd B, and Thongroy $\mathrm{P}$ (2007). Spatial and temporal variation in density and thallus morphology of Turbinaria ornata in Thailand. Aquatic Botany, 86(2):132-1388.

Rizvi AM and Shameel M (2005). Pharmaceutical biology of seaweeds from the Karachi coast of Pakistan. Pharmaceutical Biology, 43(2): 97-107.

Song XH, Zan RZ, Yu CH and Wang F (2011). Effects of modified Haizao Yuhu Decoction in experimental autoimmune thyroiditis rats. Journal of Ethnopharmacology, 135(2): 321-324.

Stirk WA, Reinecke DL and van Staden J (2007). Seasonal variation in antifungal, antibacterial and acetylcholinesterase activity in seven South African seaweeds. Journal of Applied Phycology, 19(3): 271-276.

Sun ZJ and Zhang ZE (2005). Historic perspectives and recent advances in major animal models of hypertension. Acta Pharmacologica Sinica, 26(3): 295- 301.

Tomomi F, Makio A and Akio I (2005). Preventive effects of seaweed diets on hypertension in rat. Memoirs of the Faculty of Education, Kumamoto University. Natural Science, 54: 21-25. (In Chinese) 
Van Leer EM, Seidell JC and Kromhout D (1995). Dietary calcium, potassium, magnesium and blood pressure in the Netherlands. International Journal of Epidemiology, 24(6): 1117-1123.

Yamori Y (1994). Development of the spontaneously hypertensive rat (SHR), the stroke-prone SHR
(SHRSP) and their various substrain models for hypertension-related cardiovascular diseases. In: J. D. Swales (Ed.), Handbook of hypertension, Blackwell Scientific Publication, London, UK, 16: 447-454. 